Research Article

\title{
Study on Seismic Response and Damping Measures of Surrounding Rock and Secondary Lining of Deep Tunnel
}

\author{
Baoli Tang and Yongqiang Ren $(\mathbb{D}$ \\ Department of Civil Engineering, Ordos Institute of Technology, Ordos, Inner Mongolia 017010, China \\ Correspondence should be addressed to Yongqiang Ren; ryongqiang@oit.edu.cn
}

Received 10 June 2021; Accepted 30 June 2021; Published 30 July 2021

Academic Editor: Yun Lin

Copyright (c) 2021 Baoli Tang and Yongqiang Ren. This is an open access article distributed under the Creative Commons Attribution License, which permits unrestricted use, distribution, and reproduction in any medium, provided the original work is properly cited.

\begin{abstract}
Tunnel construction is gradually developing to areas with high in situ stress; the deeper the tunnel construction, the more intense the earthquake disturbance. Under the background of frequent earthquakes, the seismic characteristics of tunnels become an important content related to the safety and stability of engineering structures. In view of the key problems of seismic response and vibration reduction measures for complex deep buried tunnels, the methods of advanced grouting and foam concrete aseismic are studied in this paper. Firstly, through geological survey, the in situ stress and geological conditions of the study area are analyzed. The structural characteristics of surrounding rock and related rock mechanics parameters are analyzed. The failure criterion of concrete lining under dynamic load is studied theoretically, and the relevant numerical calculation parameters are modified. A numerical model based on viscous boundary conditions is established. Through numerical calculation, the seismic response of tunnel surrounding rock and lining under different damping measures is analyzed. The research results have theoretical research value and social and economic benefits for ensuring the safety and stability of tunnel structure and improving the seismic fortification level.
\end{abstract}

\section{Introduction}

With the gradual transfer of tunnel construction to the high seismic intensity area, tunnel seismic has become a hot and difficult problem. How to put forward reasonable and effective seismic mitigation measures is an important purpose of tunnel seismic response analysis. In view of this, many scholars have carried out a lot of research and discussion on the mechanism and effect of seismic mitigation of tunnels and achieved rich research results. For example, Lai et al. [1] used the tunnel seismic damage investigation method combined with the Wenchuan earthquake to analyze and summarize the tunnel seismic damage. The results show that the seismic damage of fault fracture zone is the most serious, followed by tunnel entrance section and common section. The typical earthquake damages of tunnel are lining cracking, collapse, dislocation, construction joint cracking, and invert uplift. Tunnel lining crack and collapse are significant disasters caused by earthquake. Balkaya and Kalkan [2] carried out a series of modal and nonlinear static analysis of the tunnel structure, focusing on the characteristic dynamic behavior of the tunnel structure. Shen et al. [3] used the new damage assessment criteria to classify the damage degree of the detection tunnel. Then, the typical seismic damage characteristics and mechanism of mountain tunnel are analyzed from three different damage modes of shallow tunnel damage, deep tunnel structure damage, and pavement damage. Li [4] analyzed the failure characteristics of the tunnel under seismic load and divided it into collapse and landslide near the tunnel, opening cracking, lining, and surrounding rock collapse, lining cracking and dislocation, ground uplift and cracking, and initial support deformation and cracking. Miao et al. [5] adopted the concept of the response displacement method and realized it with a fine free field model and a simplified soil tunnel model in order to efficiently study the seismic characteristics of this special subway tunnel under the action of spatial ground motion.

Mayoral et al. [6] used FLAC3D to evaluate the seismic response of a typical tunnel shaft under the condition of increasing seismic intensity. Gan et al. [7] used the discrete 
element numerical analysis method to analyze the control effect of the support on the surrounding rock of the tunnel. Vanuvamalai et al. [8] evaluated the seismic performance of tunnel structure by studying the seismic vulnerability of underground tunnel. Hui et al. [9] designed a large-scale shaking table slope model test with the geometric scale of 1 : 10. The Wenchuan earthquake wave was used as the excitation wave in the model test in order to study the mechanical characteristics of shallow bias tunnel with small clear distance under earthquake. Li et al. $[10,11]$ analyzed the development of plastic zone of surrounding rock under the condition of different grouting thicknesses and calculated the distribution characteristics of in situ stress field by using the neural network inversion method. In terms of numerical computation, Meng et al. [12] established an open source software package for modeling inhomogeneous materials based on digital image processing.

In terms of experiments, Zhu et al. [13] tested the collision of different shapes of rolling stones with protective mats in an open pit mine. Yin et al. [14] analyzed the shear mechanical response of sandstone at high temperature under normal stiffness boundary conditions. In terms of engineering application research, Wang et al. $[15,16]$ investigated deep mine autocuttings with high-strength bolted grouted roof cuts using numerical simulations, indoor experiments, and other methods. Wang et al. [17] studied the fracture evolution and energy characteristics during marble damage under triaxial fatigue cycling and constrained pressure unloading (FC-CPU) conditions.

In this paper, through geological investigation and numerical analysis, the force characteristics of tunnel surrounding rock and lining under the action of earthquake load are studied and the method to reduce the effect of earthquake on the tunnel and determine the control parameters of the response is proposed.

\section{Engineering Geological Conditions}

2.1. Geological Characteristics. Yuelongmen tunnel of China Chenglan railway crosses the Northeast Longmenshan mountain range, and the intersection angle between the tunnel crossing section and the mountain range is about $60^{\circ}$. The Longmenshan structural belt crossed by Yuelongmen tunnel is a huge nappe structural belt with large scale and complex structure. The overall trend is NE $45^{\circ}$. It stretches $500 \mathrm{~km}$ and is $25-50 \mathrm{~km}$ wide. There are three main faults from east to west: Longmen Qianshan fault, Longmen central fault, and Longmen Houshan fault. The direction of tectonic movement is NW-SE upthrusting, forming three imbricate thrust belts. The terrain is NW-SE descending step by step, and the relative height difference is $600-700 \mathrm{~m}$. The whole tunnel is located in the Longmenshan seismic zone, which is one of the concentrated areas of active faults and strong earthquakes, including the Longmenshan, Minjiang, West Qinling, and other seismic zones, which are prone to high intensity earthquakes in Western China (Figure 1). The famous Wenchuan earthquake still has frequent aftershocks. The lithology of surrounding rock is mainly phyllite, carbonaceous slate, and shale, with local diabase dyke intrusion, soft rock, broken rock, water saturated surrounding rock, rock softening with water, and low strength.

2.2. In Situ Stress Characteristics. The in situ stress test was carried out at DK107+520 of Yuelongmen tunnel. The designed hole depth is $605 \mathrm{~m}$. The core drilled in this hole is mainly carbonaceous phyllite. The test results are shown in Figure 2.

Based on the test results, the basic characteristics of in situ stress of Yuelongmen tunnel are analyzed. The maximum horizontal principal stress near the tunnel body is about $16 \mathrm{MPa}$, the minimum horizontal principal stress is about $12 \mathrm{MPa}$, and the vertical principal stress calculated by overlying strata is about $16 \mathrm{MPa}$. The relationship between the value of the principal stress in the direction of air near the tunnel body is $S_{H}>S_{V}>S_{h}$. The in situ stress is mainly characterized by regional tectonic stress, while the difference between the vertical stress and the maximum horizontal principal stress is between 4 and $6 \mathrm{MPa}$. The distribution of principal stress with depth is shown in Figure 2. It can be seen that the three-dimensional principal stress increases with depth. In order to quantitatively analyze the relationship between the stress value and the depth of the hole, the linear regression method is used to calculate the regression of the hole, and the results are as follows $[18,19]$ :

$$
\begin{array}{rl}
S_{H}=0.021 D+4.33 & R=0.9016, \\
S_{h}=0.016 D+2.38 & R=0.9309, \\
S_{V}=0.0265 D . &
\end{array}
$$

2.3. Mechanical Properties of Surrounding Rock. The surrounding rock of the section is mainly phyllite, with higher mica content, smaller particle size, and directional arrangement. The texture is developed, and the fabric surface can be seen with silk luster. The sandy phyllite is dark gray with crystallite structure and sheet structure. The grain size of mineral particles is small, and the schistosis of rock is developed, and silk luster can be seen on the foliation surface. Phyllite mineral distribution has a strong direction of optimization. According to the mineral analysis, the main minerals of the phyllite sample are as follows: illite content is $14 \%-59 \%$; quartz content is $3 \%-68 \%$; and chlorite content is $3 \%-61 \%$.

The carbonaceous phyllite was studied by $0^{\circ}$ and $90^{\circ}$. The stress-strain curve of the triaxial compression test under inclination angle is shown in Figure 3. The confining pressure was set to $5 \mathrm{MPa}, 15 \mathrm{MPa}$, and $20 \mathrm{MPa}$, respectively. The loaded specimens at $0^{\circ}$ and $90^{\circ}$ inclination angles exhibit two different deformation characteristics. The former specimens have no obvious peak strength and strain softening stages under different envelope pressures and macroscopically present compression-based ductile expansion damage. The latter has the characteristics of hard rock damage, the peak strength strain is lower, the residual strength increases with the increase in the surrounding pressure, and the specimens mostly have tension damage as 


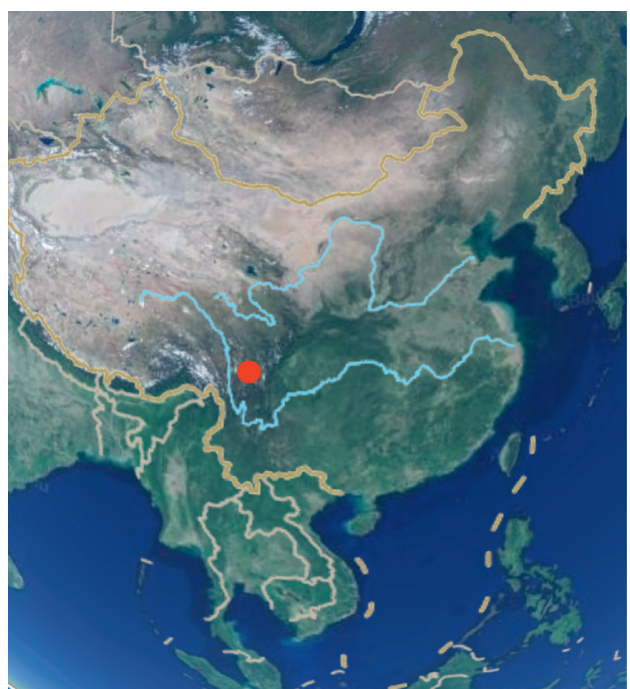

(a)

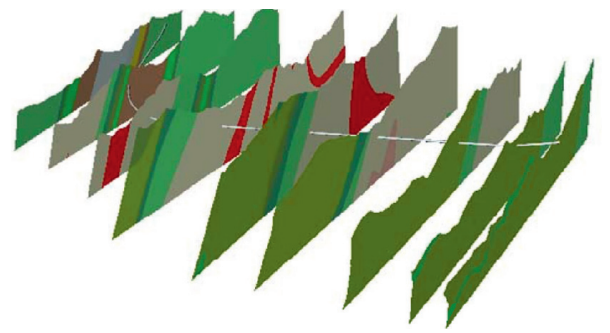

(b)

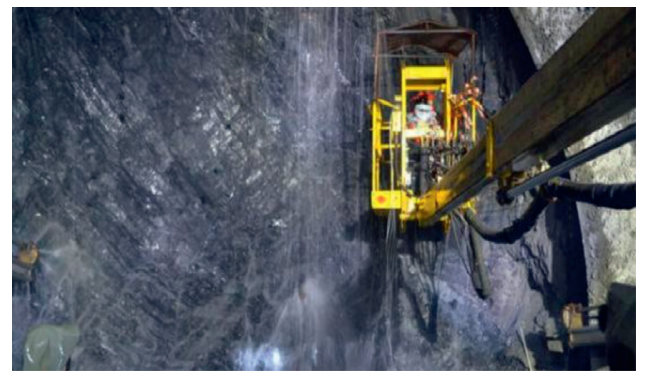

(c)

FIGURE 1: Engineering geological characteristics of Yuelongmen deep buried tunnel: (a) tunnel location; (b) tunnel crossing stratum; (c) characteristics of surrounding rock.

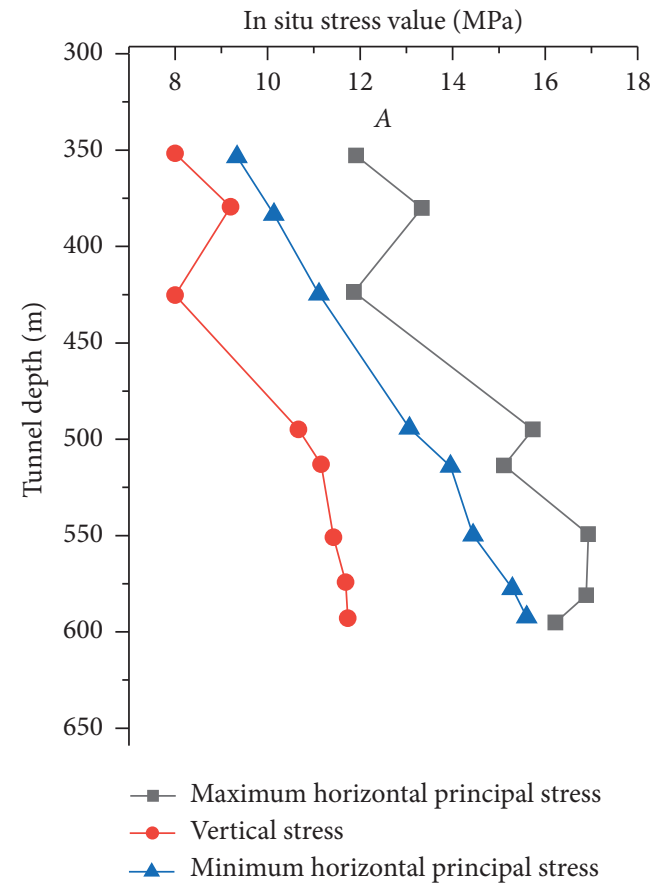

(a)

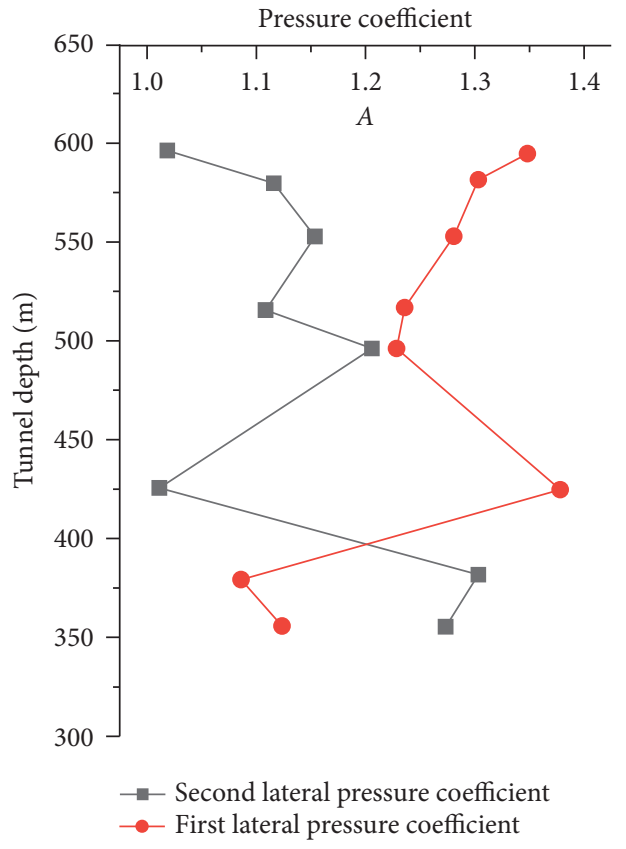

(b)

Figure 2: In situ stress test results: (a) in situ stress depth relationship; (b) lateral pressure coefficient depth relationship. 


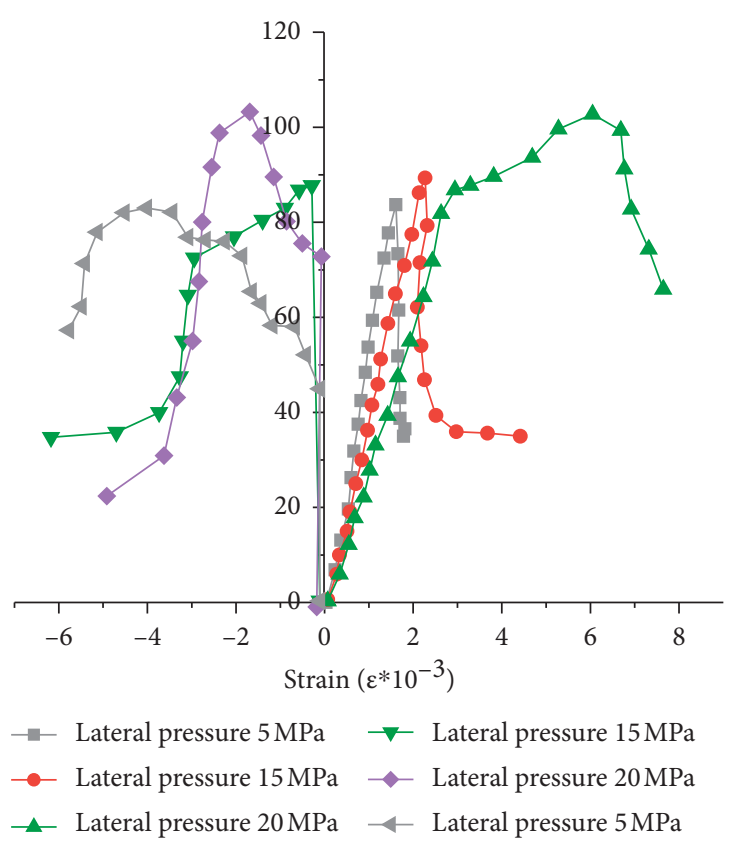

(a)

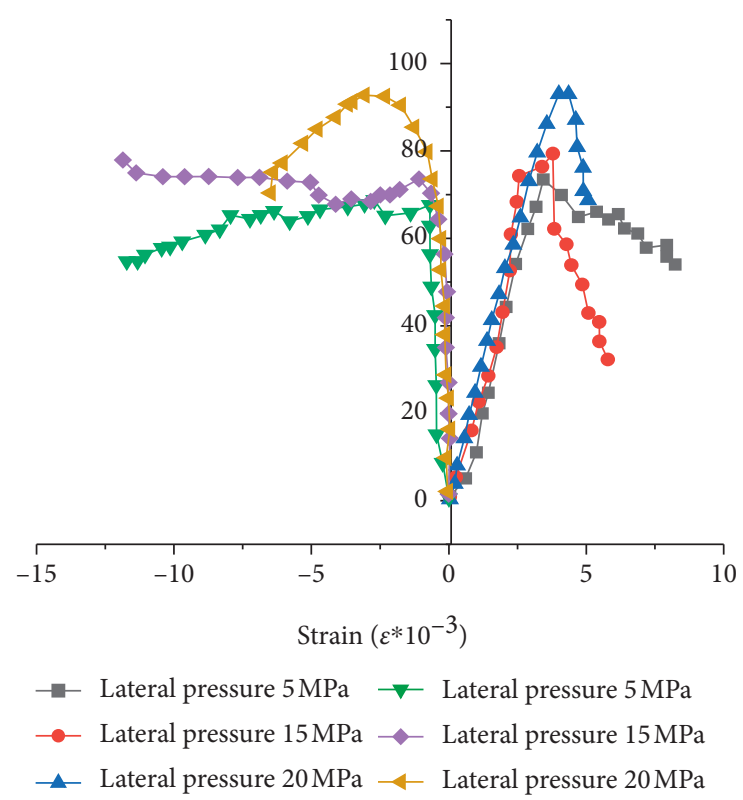

(b)

Figure 3: Typical stress-strain curves for triaxial compression of carbonaceous micaceous rocks: (a) joint dip $0^{\circ}$; (b) joint dip $90^{\circ}$.

the main damage mode. According to the experimental results, it is known that when the joints are at $0^{\circ}$ dip angle, the peak strength of carbonaceous slate is $85 \mathrm{MPa}$ under the confining pressure of $5 \mathrm{MPa}$. The peak strength is $90 \mathrm{MPa}$ at a confining pressure of $15 \mathrm{MPa}$ and $104 \mathrm{MPa}$ at a confining pressure of $20 \mathrm{MPa}$. When the joints are $90^{\circ}$ dip, the peak strength of carbonaceous slate is $73 \mathrm{MPa}$ at a confining pressure of $5 \mathrm{MPa}, 80 \mathrm{MPa}$ at a confining pressure of $15 \mathrm{MPa}$, and $95 \mathrm{MPa}$ at a confining pressure of $20 \mathrm{MPa}$.

\section{Tunnel Concrete Lining Dynamic Damage Cracking Model}

According to the relevant research results, there are differences between the dynamic and static constitutive models of concrete, as shown in Figure 4. Curve 1 represents the static constitutive model, and curve 2 represents the dynamic constitutive model. The two models satisfy the geometric relation 2 .

$$
\frac{A B}{C d}=\frac{O A}{O C}
$$

It is assumed that the constitutive relation of concrete under dynamic load is as follows [20-22]:

$$
\sigma_{d}=E_{d} \varepsilon\left(1-D_{d}\right)
$$

where $E_{d}$ is the dynamic elastic modulus of concrete, which can be replaced by the static elastic modulus, and $D_{d}$ is a dynamic damage variable.

According to formulas (2) and (3), the following formula is obtained:

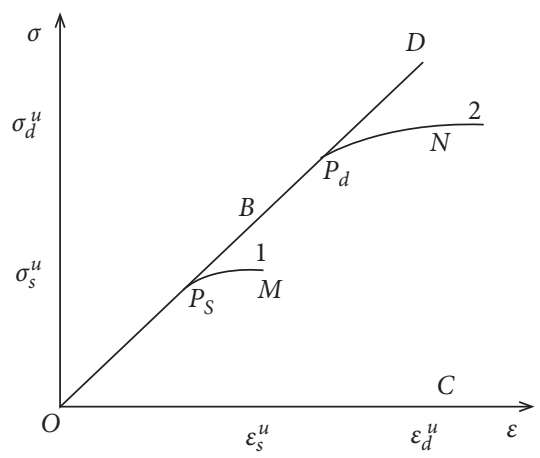

FIgure 4: Static and dynamic constitutive relation curve of concrete.

$$
\begin{aligned}
{\left[1-D_{d}\left(\varepsilon_{d}^{u}\right)\right] } & =\frac{f_{\sigma}(\dot{\varepsilon})}{f_{\varepsilon}(\dot{\varepsilon})}\left[1-D_{s}\left(\varepsilon_{s}^{u}\right)\right], \\
f_{\sigma}(\dot{\varepsilon}) & =\frac{\sigma_{d}^{u}}{\sigma_{s}^{u}} \\
f_{\varepsilon}(\dot{\varepsilon}) & =\frac{\varepsilon_{d}^{u}}{\varepsilon_{s}^{u}} .
\end{aligned}
$$

In the formula, $\sigma_{d}^{u}$ and $\varepsilon_{d}^{u}$ are the dynamic damage limit stress and strain of concrete, respectively, and $\sigma_{s}^{u}$ and $\varepsilon_{s}^{u}$ are the static damage limit stress and strain of concrete, respectively.

The dynamic damage threshold strain of concrete is proportional to the static damage threshold strain, and the static damage threshold strain is $\varepsilon_{s}^{0}[23,24]$. The concrete dynamic damage threshold value method is shown in 
formula (6), and then the concrete dynamic damage constitutive equation (7) is obtained.

$$
\begin{gathered}
\varepsilon_{d}^{0}=f_{\varepsilon}(\dot{\varepsilon}) \varepsilon_{s}^{0}, \\
\begin{cases}\sigma_{d}=E_{d} \varepsilon, & \varepsilon \leq \varepsilon_{d}^{0}, \\
\sigma_{d}=E_{d} \varepsilon \frac{f_{\sigma}(\dot{\varepsilon})}{f_{\varepsilon}(\dot{\varepsilon})}\left[1-D_{s}\left(\frac{\varepsilon}{f_{\varepsilon}(\dot{\varepsilon})}\right)\right], & \varepsilon>\varepsilon_{d}^{0} .\end{cases}
\end{gathered}
$$

The response process of tunnel lining and surrounding rock under earthquake action involves three kinds of media. The media include surrounding rock, lining, and air in tunnel. There are two kinds of interfaces, the interface between tunnel lining and surrounding rock and the lining free surface.

\section{Numerical Calculation Model and Boundary Conditions}

4.1. Model Establishment. In the study of vibration load action analysis, the distance between the boundary conditions and the study target has a more serious influence on the calculation results. Theoretically, the smaller the selected range is, the less accurate the analysis results are, but too large a model range will cause inconvenience to the computational analysis and too long analysis time may also lead to interruption of the analysis.

In this paper, we use $3 \mathrm{DEC}$, a computational analysis program based on the discrete unit method as the basic theory to describe the mechanical behavior of discrete media. The rock mass has different lithological properties of rock masses (continuum) and geological structural surfaces (discontinuous features), and under the action of external forces, the rock masses can behave as a continuous media mechanical behavior, while the rock masses interact with each other through the structural surfaces (discontinuous features). When the force on the structural surface exceeds its load-bearing limit, the rock masses will show realistic damage phenomena such as mutual shearing and misalignment or dislocation.

We selected several models with different ranges of surrounding rocks and performed seismic dynamic response analysis to determine the influence of different ranges of surrounding rocks on tunnel stability and concluded that the results of the study tend to be stable when a model with a range greater than 3 times the tunnel width is selected. When the model boundary conditions and the actual situation are different, it will lead to the error of calculation results because of the error of calculating the model boundary conditions, and this calculation error is called the boundary effect. In this paper, the seismic dynamic response analysis of the Leaping Dragon Tunnel cavern section was carried out for the following model ranges: $x$-direction (horizontal direction) $80 \mathrm{~m}, y$-direction (tunnel direction) $40 \mathrm{~m}$, and $z$ direction (tunnel vertical direction) $80 \mathrm{~m}$, as shown in Figure 5.
4.2. Selection of Calculation Parameters. Solid units are used to model the tunnel envelope, primary lining, and secondary lining. In order to better simulate the interaction between the tunnel surrounding rock and the lining system, solid units are used. The initial lining is supported by sprayed C30 concrete and the secondary lining by C30 concrete.

For the dynamic analysis of the structure, the mechanical properties of the surrounding rock and materials change under the dynamic load, and the mechanical calculation parameters change accordingly, so the dynamic parameters should be used for the analysis of the seismic dynamic response of the secondary lining of the tunnel opening section.

According to the analysis of the relevant literature, the relationship between the dynamic modulus and static modulus of elasticity satisfies formula (8) where $E_{s}$ is the static modulus of elasticity and $E_{d}$ is the dynamic modulus of elasticity, and dynamic parameters are shown in Table 1.

$$
E_{s}=0.025 E_{d}^{1.7} \text {. }
$$

\subsection{Boundary Conditions and Vibration Load Loading.}

For this numerical calculation, the viscoelastic artificial boundary is used for the boundary conditions. The elastic artificial boundary condition ensures that its stress state is consistent with the theoretical value obtained from the solution of the fluctuation equation by means of fictitious spring and damper elements. The normal simulation of the artificial boundary is achieved by applying a spring-damper concentrated mass system to the model boundary.

Based on the kinematic principle, the basic differential equations of stress and displacement of the nodes on the artificial boundary after applying the physical system can be derived, as shown in the following equation:

$$
\sigma+\frac{M}{C} \frac{\partial \sigma}{\partial t}=K\left(u_{R}+\frac{M}{C} \frac{\partial u_{R}}{\partial t}+\frac{M}{C} \frac{\partial^{2} u_{R}}{\partial t^{2}}\right) .
$$

The parameters of the applied physical system components satisfy the following:

$$
\begin{gathered}
K=\frac{4 G}{R}, \\
C=\rho c_{p}, \\
M=\rho R .
\end{gathered}
$$

In the equation, $u_{R}$ is the displacement of the artificial boundary node under the load.

The spring + damper system is used to simulate the tangential artificial boundary, and the physical element parameters satisfy the following equation:

$$
\begin{aligned}
K & =\frac{2 G}{R}, \\
C & =\rho c_{s} .
\end{aligned}
$$




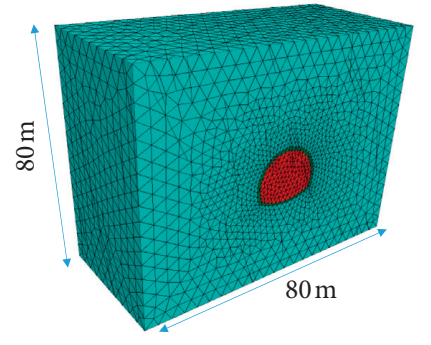

(a)

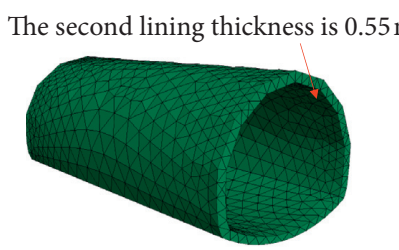

(b)

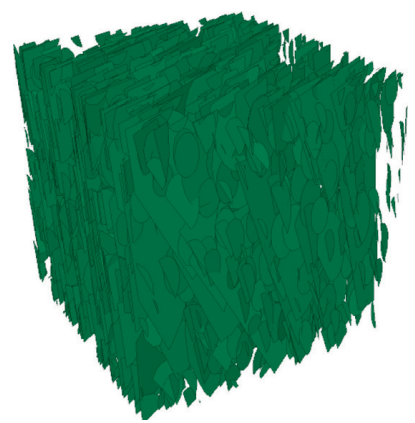

(c)

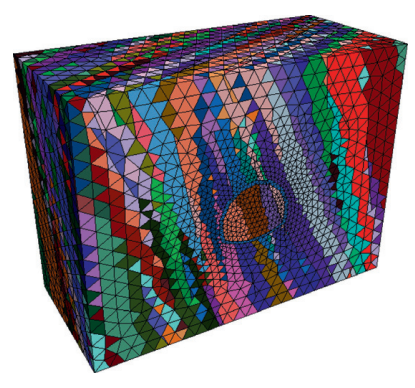

(d)

FIGURE 5: Numerical simulation model: (a) numerical calculation model; (b) tunnel lining; (c) distribution characteristics of joints in surrounding rock; (d) tunnel surrounding rock.

TABle 1: Rock dynamics parameters.

\begin{tabular}{|c|c|c|c|c|}
\hline Name & Surrounding rock & Anchor & Initial support & Tunnel lining \\
\hline Modulus of elasticity $E(\mathrm{~Pa})$ & $1.64 e^{9}$ & $198 e^{9}$ & $23.5 e^{9}$ & $30.78 e^{9}$ \\
\hline Poisson's ratio $\mu$ & 0.42 & 0.23 & 0.24 & 0.22 \\
\hline Weight $\rho\left(\mathrm{kg} / \mathrm{m}^{3}\right)$ & 18.33 & 25.32 & 23.16 & 23.33 \\
\hline Cohesion $C(\mathrm{MPa})$ & 0.19 & & & \\
\hline Angle of internal friction $p\left(^{\circ}\right)$ & 23 & & & \\
\hline
\end{tabular}

Simulating the vertical incidence at the bottom of the $\mathrm{P}$-wave, the seismic intensity of the area where the Yuelongmen tunnel is located is 8 degrees, and the duration of the seismic wave is $5-10$ times of the basic vibration period of the structure, and the seismic waveform is shown in Figure 6.

\section{Tunnel Seismic Mitigation Measures}

5.1. Influence of Grouting Reinforcement of Surrounding Rock on Seismic Effect. The response of grouting thickness to tunnel structure under seismic load is analyzed. Taking different grouting thicknesses under the condition of contact grouting as the research objective, the influence of different grouting thicknesses on surrounding rock is analyzed. After grouting, the elastic modulus of surrounding rock is increased by $55 \%$ and the cohesion is increased by $60 \%$. The grouting scheme is shown in Figure 7.

The development law of damage volume of rock around the cave under different grouting thickness conditions is shown in Figure 8. According to the numerical calculation results, it can be seen that with the increase in grouting thickness, the area of plastic zone per unit length of tunnel boring decreases gradually. However, the reduction trend slows down gradually, and the plastic zone decreases by $13 \%$ when the grouting thickness is from $0 \mathrm{~m}$ to $1 \mathrm{~m}$. From $1 \mathrm{~m}$ to $2 \mathrm{~m}$, the plastic zone decreases by $10 \%$. The plastic zone decreases by $6 \%$ from $2 \mathrm{~m}$ to $3 \mathrm{~m}$. The plastic zone is reduced by $5 \%$ from $3 \mathrm{~m}$ to $4 \mathrm{~m}$. The plastic zone is reduced by $2.5 \%$ when the grouting thickness is from $4 \mathrm{~m}$ to $5 \mathrm{~m}$. Considering the economic efficiency, the reasonable grouting thickness should be $4 \sim 5 \mathrm{~m}$.
Figure 9 shows the deformation of the second liner under different grouting thicknesses. With the increase in grouting thickness, the deformation of vault top, arch waist, and arch bottom is gradually reduced. Similar to the development of plastic zone, the decrease is gradually reduced.

5.2. Polyethylene Foam Damping Materials on the Seismic Effect of the Tunnel. The polyethylene foam damping material is laid between the lining structure and the rock around the cave, and the lining is separated from the surrounding rock by the damping layer, to reduce and change the intensity and mode of action of the earthquake on the lining structure and to reduce the dynamic response of the lining structure, and its arrangement is shown in Figure 10. The polyethylene foam damping material takes the value of the elastic modulus as $6 \mathrm{MPa}$ and Poisson's ratio as 0.38 .

Figures 11 and 12 show the stresses and deformations of the tunnel lining under the protection of different thicknesses of vinyl foam damping materials. The thickness of polyethylene foam is set in four gradients, $0.05 \mathrm{~m}, 0.1 \mathrm{~m}$, $0.2 \mathrm{~m}$, and $0.3 \mathrm{~m}$. As shown in Figure 11, the maximum principal stress of the second liner decreases gradually with the increase in the thickness of the damping layer. The effect of $0.2 \mathrm{~m}$ thickness protective layer and $0.3 \mathrm{~m}$ thickness protective layer basically overlaps. Figure 12 shows that the deformation of the tunnel second liner gradually decreases with the increase in the thickness of the damping layer. Taking the right arch waist as an example, the deformation decreases by $5 \%$ when the thickness of the damping layer increases from $0 \mathrm{~m}$ to $0.05 \mathrm{~m}$. When the thickness of the damping layer increases from $0.05 \mathrm{~m}$ to $0.1 \mathrm{~m}$, the deformation decreases by $7 \%$. When the thickness of the damping 


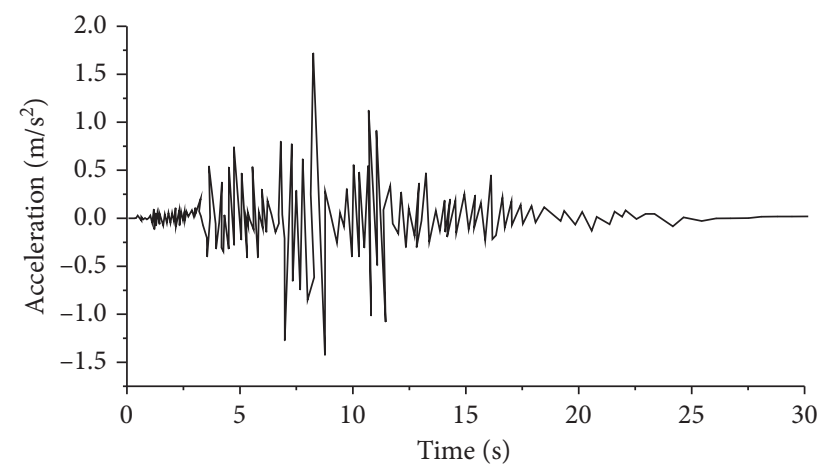

Figure 6: Seismic wave P-waveform.

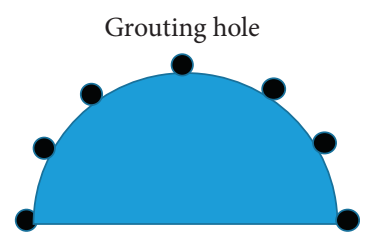

(a)

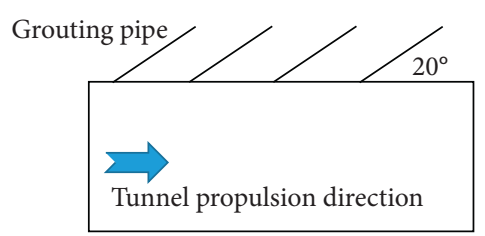

(b)

Figure 7: Surrounding rock reinforcement grouting process: (a) front view and (b) side view.

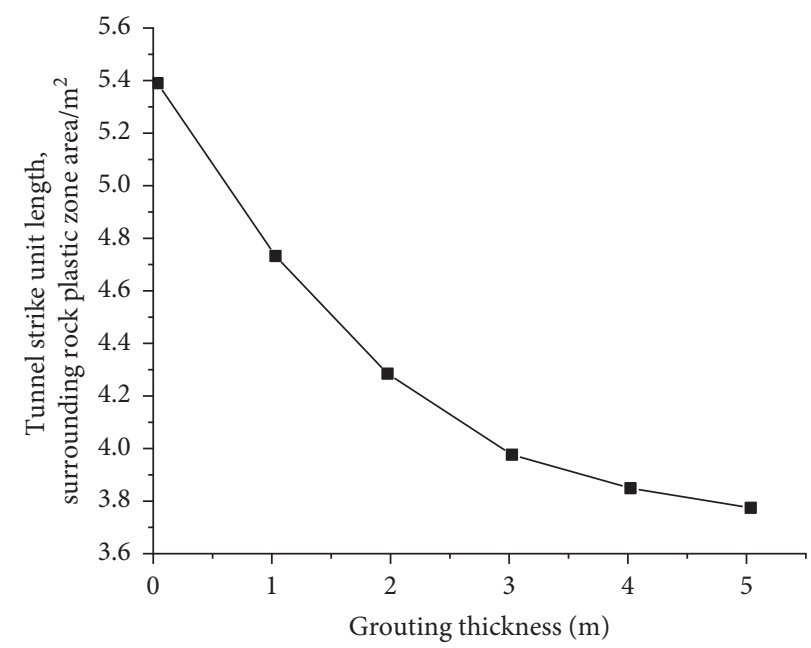

FIgURE 8: Area of plastic zone of surrounding rock under the action of different grouting thicknesses.

layer increases from $0.1 \mathrm{~m}$ to $0.2 \mathrm{~m}$, the deformation decreases by $3 \%$. When the thickness of the damping layer is increased from $0.2 \mathrm{~m}$ to $0.3 \mathrm{~m}$, the deformation is reduced by
$1.4 \%$. Through the analysis of the second liner force and second liner deformation, the selection of $0.2 \mathrm{~m}$ thickness of vinyl foam damping material has strong economic value. 


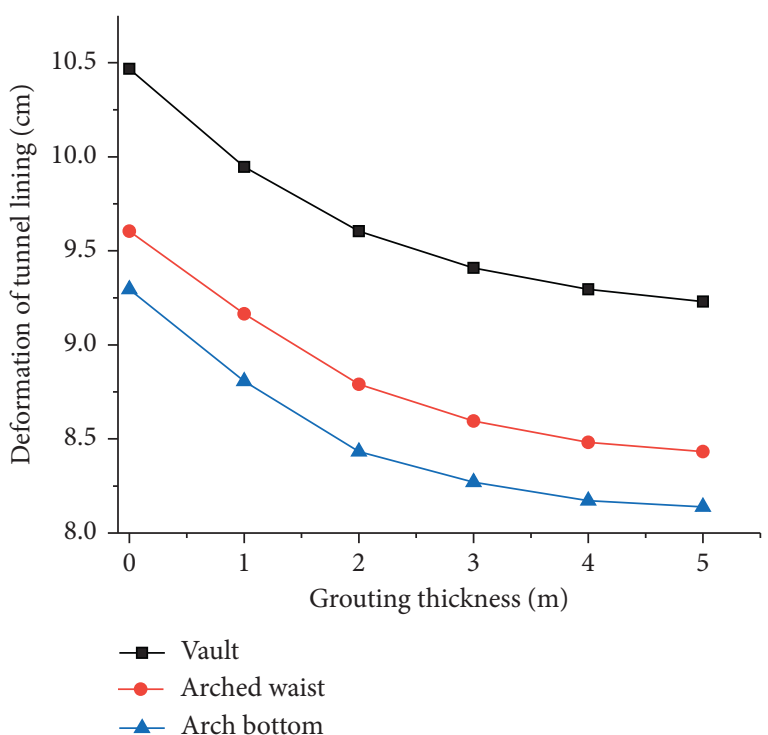

FIGURE 9: Deformation of the second liner under the action of different grouting thicknesses.

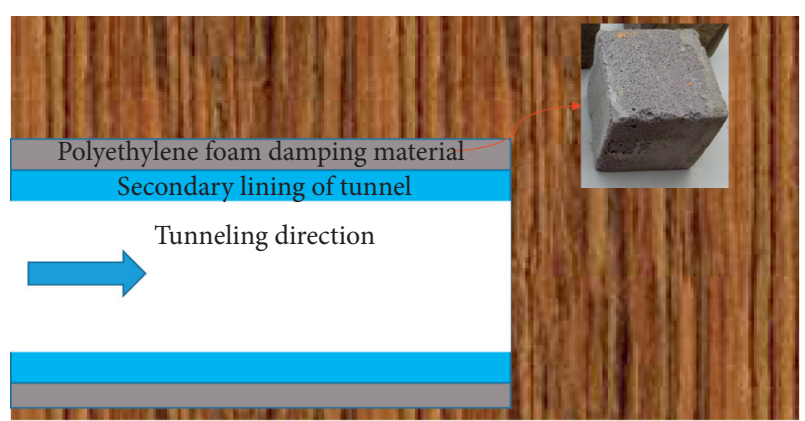

FIgURe 10: Arrangement of polyethylene foam vibration damping material in the tunnel.

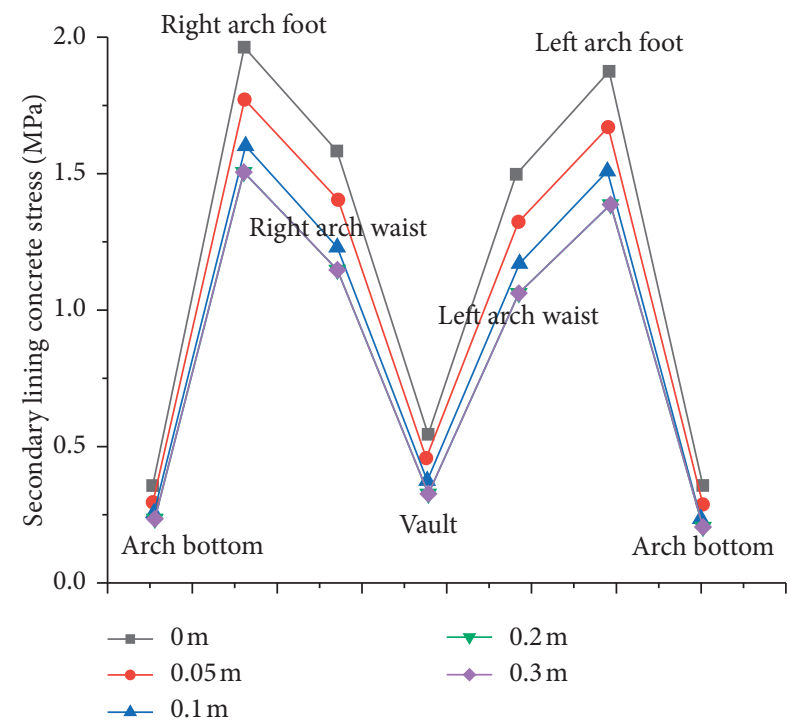

Figure 11: The maximum principal stress of lining structure.

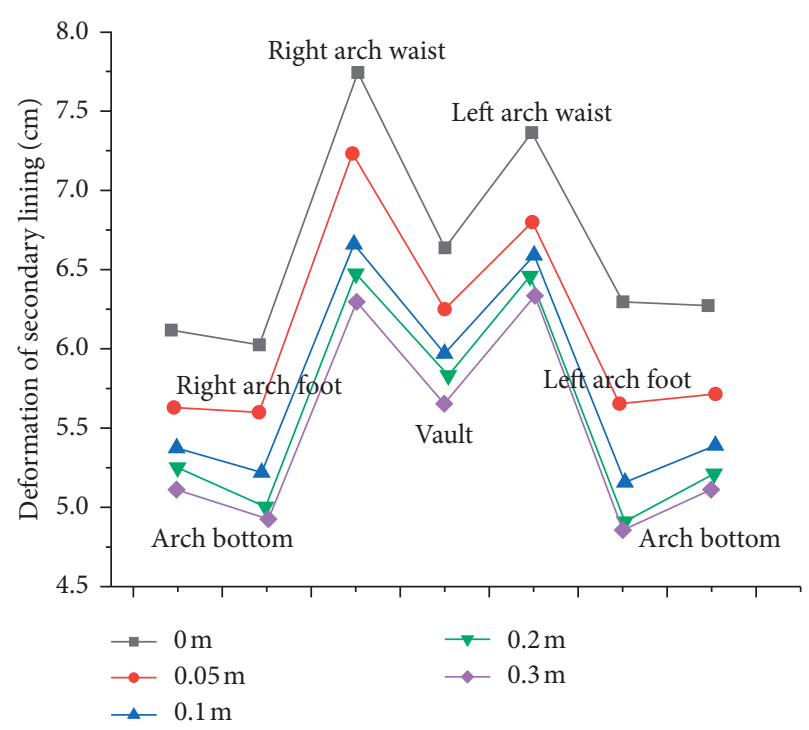

FIGURE 12: Lining displacement under different thicknesses of the damping layer.

\section{Conclusion}

Through the analysis of the in situ stress test, the characteristics of in situ stress $n$ of the area of the Yuelongmen tunnel were obtained, and the study concluded that the area is dominated by horizontal in situ stress. The cracking criterion of the second lining concrete under dynamic load was established, and the numerical calculation model was constructed considering the mechanical parameters of the material under dynamic load, and the artificial viscous boundary was adopted as the boundary condition. The effects of two methods, grouting reinforcement and vinyl foam damping material, on the seismic effect of the tunnel were analyzed, and the study showed that both methods had good effects. However, with the increase in tunnel reinforcement area and buffer layer thickness, the seismic damping effect tends to weaken. A reasonable thickness of grouting should be $4 \sim 5 \mathrm{~m}$, and the thickness of the buffer layer of damping material should be $0.2 \mathrm{~m}$.

\section{Data Availability}

The data used to support the findings of this study are available from the corresponding author upon request.

\section{Conflicts of Interest}

The authors declare that they have no conflicts of interest to report regarding the present study.

\section{Acknowledgments}

The research was funded by Natural Science Foundation of Inner Mongolia Province (No. 2020MS04006) and Key Projects of Ordos Institude of Technology (No. KYZD2019002). 


\section{References}

[1] J. Lai, S. He, J. Qiu et al., "Characteristics of seismic disasters and aseismic measures of tunnels in Wenchuan earthquake," Environmental Earth Sciences, vol. 76, no. 2, p. 94, 2017.

[2] C. Balkaya and E. Kalkan, "Seismic vulnerability, behavior and design of tunnel form building structures," Engineering Structures, vol. 26, no. 14, pp. 2081-2099, 2004.

[3] Y. Shen, B. Gao, X. Yang, and S. Tao, "Seismic damage mechanism and dynamic deformation characteristic analysis of mountain tunnel after Wenchuan earthquake," Engineering Geology, vol. 180, pp. 85-98, 2014.

[4] T. Li, "Damage to mountain tunnels related to the Wenchuan earthquake and some suggestions for aseismic tunnel construction," Bulletin of Engineering Geology and the Environment, vol. 71, no. 2, pp. 297-308, 2012.

[5] Y. Miao, E. Yao, B. Ruan, and H. Zhuang, "Seismic response of shield tunnel subjected to spatially varying earthquake ground motions," Tunnelling and Underground Space Technology, vol. 77, pp. 216-226, 2018.

[6] J. M. Mayoral, S. Argyroudis, and E. Castañon, "Vulnerability of floating tunnel shafts for increasing earthquake loading," Soil Dynamics and Earthquake Engineering, vol. 80, pp. 1-10, 2016.

[7] L. Gan, M. Weibin, T. Siming, and Z. Wenhao, "Effects of high-pretension support system on soft rock large deformation of perpendicularly crossing tunnels," Advances in Civil Engineering, vol. 2020, pp. 1-18, 2020.

[8] A. Vanuvamalai, K. P. Jaya, and V. Balachandran, "Seismic performance of tunnel structures: a case study," Natural Hazards, vol. 93, no. 1, pp. 453-468, 2018.

[9] Y. Hui, J. Xueliang, and L. Pengyuan, "Seismic response of tunnel lining for shallow-bias tunnel with a small clear distance under Wenchuan earthquake," Advances in Civil Engineering, vol. 2018, pp. 1-10, 2018.

[10] G. Li, W. Ma, S. Tian, Z. Hongbo, F. Huabin, and W. Zou, "Groundwater inrush control and parameters optimization of curtain grouting reinforcement for the jingzhai tunnel," Geofluids, vol. 2021, pp. 1-10, 2021.

[11] G. Li, Y. Hu, Q.-B. Li, T. Yin, J.-X. Miao, and M. Yao, "Inversion method of in-situ stress and rock damage characteristics in dam site using neural network and numerical simulation-A case study," IEEE Access, vol. 8, pp. 4670146712, 2020.

[12] Q.-X. Meng, W.-Y. Xu, H.-L. Wang, X.-Y. Zhuang, W.-C. Xie, and T. Rabczuk, "DigiSim - an open source software package for heterogeneous material modeling based on digital image processing," Advances in Engineering Software, vol. 148, Article ID 102836, 2020.

[13] C. Zhu, M.-C. He, M. Karakus, X.-H. Zhang, and Z. Guo, "The collision experiment between rolling stones of different shapes and protective cushion in open-pit mines," Journal of Mountain Science, vol. 18, no. 5, pp. 1391-1403, 2021.

[14] Q. Yin, J. Wu, C. Zhu, M. He, Q. Meng, and H. Jing, "Shear mechanical responses of sandstone exposed to high temperature under constant normal stiffness boundary conditions," Geomechanics and Geophysics for Geo-Energy and GeoResources, vol. 7, no. 2, p. 35, 2021.

[15] Q. Wang, Z. Jiang, B. Jiang, H. Gao, Y. Huang, and P. Zhang, "Research on an automatic roadway formation method in deep mining areas by roof cutting with high-strength boltgrouting," International Journal of Rock Mechanics and Mining Sciences, vol. 128, Article ID 104264, 2020.
[16] Q. Wang, Y. Wang, M. He et al., "Experimental research and application of automatically formed roadway without advance tunneling," Tunnelling and Underground Space Technology, vol. 114, no. 3, Article ID 103999, 2021.

[17] Y. Wang, W. K. Feng, R. L. Hu, and C. H. Li, "Fracture evolution and energy characteristics during marble failure under triaxial fatigue cyclic and confining pressure unloading (FC-CPU) conditions," Rock Mechanics and Rock Engineering, vol. 54, no. 2, pp. 799-818, 2021.

[18] A. Li, F. Dai, Y. Liu, H. Du, and R. Jiang, "Dynamic stability evaluation of underground cavern sidewalls against flexural toppling considering excavation-induced damage," Tunnelling and Underground Space Technology, vol. 112, Article ID 103903, 2021.

[19] F. Wu, R. Gao, J. Liu, and C. Li, "New fractional variable-order creep model with short memory," Applied Mathematics and Computation, vol. 380, Article ID 125278, 2020.

[20] F. Wu, H. Zhang, Q. Zou, C. Li, J. Chen, and R. Gao, "Viscoelastic-plastic damage creep model for salt rock based on fractional derivative theory," Mechanics of Materials, vol. 150, Article ID 103600, 2020.

[21] J. Huang, Y. Zhang, Y. Tian et al., "Research on the dynamic mechanical properties and constitutive models of steel fiber reinforced concrete and polypropylene fiber reinforced concrete," Advances in Civil Engineering, vol. 2020, pp. 1-17, 2020.

[22] X. Cong, W. Zhou, and M. Elchalakani, "Experimental study on the engineering properties of alkali-activated GGBFS/FA concrete and constitutive models for performance prediction," Construction and Building Materials, vol. 240, Article ID 117977, 2020.

[23] L. Ma, F. Wang, P. Cui, M. Yunusa, and Y. Xiao, "Effect of aging on the constitutive models of asphalt and their mixtures," Construction and Building Materials, vol. 272, Article ID 121611, 2021.

[24] J. Lai and W. Sun, "Dynamic behaviour and visco-elastic damage model of ultra-high performance cementitious composite," Cement and Concrete Research, vol. 39, no. 11, pp. 1044-1051, 2009. 